\title{
Negative incentive contrast effects with sucrose and rats as due to aggression
}

\author{
LAWRENCE WEINSTEIN \\ Brandon University, Brandon, Manitoba R7A 6A9, Canada
}

\begin{abstract}
Three equal groups ( $n=20$ each) of rats received 10 sessions of barpress training for $16 \%$ or $4 \%$ sucrose solutions or tap water. On Session 11, the 16\% group was changed to a $4 \%$ (constant volume) sucrose solution. Negative contrast occurred. Moreover, on the postshift days, the number of times the downshifted subjects bit a bottle brush was statistically greater than the control group, indicating greater aggression in the shifted than in the nonshifted animals. Furthermore, the shifted subjects displayed no frustration effect in the double runway. These data, together with one other study in the literature, speak to an aggression account of the downward contrast effect rather than a frustrative account of the negative phenomenon. Future research should provide further validity information on the two dependent measures used herein.
\end{abstract}

Negative incentive contrast effects in animals occur when a reduction in amount of reward produces a significantly lower level of behavior than the level of a control group maintained on the smaller reward magnitude throughout training. One of the most typical (frequently employed) explanations of the downward phenomenon in rats is the Amsel-Spence frustration hypothesis or some extension there of (Amsel, 1958; Spence, 1960; Weinstein, 1972). In general, the frustration accounts of negative contrast argue that when reward is less than the expected amount, general, or overall, behavioral vigor increases. Some of the responses that are said to be heightened in reply to a reduction in reward constitute competing responses that are hypothesized to produce decrements in the instrumental response below the low reward level. However, few (if any) direct, empirical, observations have been made as to the actual existence of frustration responses (overall performance increases) consequent to decreases in reinforcement amount. Such investigations should look for overall, gross, increases in behavior attendant upon reductions in incentive magnitude.

With little (if any) direct empirical observation of such competing frustration responses, an at least equally plausible explanation of the depression phenomenon is that it is due to aggression. As distinct from frustration replies, aggressive responses are of a particular type and do not involve overall level of activity in animals. The aggression hypothesis presented herein maintains that a reduction in reward quantity produces an aggressive response increase only, and not an overall response increase; the augmentation in the aggressive behavior, then, interferes with the instrumental response to produce the downward incentive effect.

Requests for reprints should be sent to Dr. L. Weinstein, Department of Psychology, Brandon University, Brandon, Manitoba R7A 6A9, Canada.
The present investigation examined the effects of reducing the magnitude of reward on barpressing, aggressive, and runway behavior, the last representing an indicant of overall general activity level. If a reward reduction produces negative contrast, and the downshifted subjects immediately then exhibit more aggressive replies than but the same running performance as animals in the constant reward-amount control group, then it would seem that the negative effect is due to aggression rather than frustration.

\section{METHOD}

\section{Subjects}

The subjects, 60 experimentally naive male albino rats, 80 92 days of age at the start of the experiment, were housed in individual cages and randomly assigned to each of three equal groups, so that 20 animals appeared in each group.

\section{Apparatus}

The operant box had plywood side walls, Plexiglas top, back, and door, and a grid floor. It generally consisted of a dipper delivering liquid sucrose for $2 \mathrm{sec}$ for every press of a bar. The operant chamber is more fully described in Weinstein (1970b). Another apparatus consisted of a straight-alley runway. The floor of the runway was made of plywood $9.5 \mathrm{~mm}$ thick. Walls were $20.3 \mathrm{~cm}$ high and painted flat gray. Each of three sections was covered with a hinged Plexiglas lid. The $30.5-\mathrm{cm}$ startbox and the $122-\mathrm{cm}$ alley, $12 \mathrm{~cm}$ wide, were separated by a guillotine Plexiglas door. A Plexiglas guillotine door separated the alley and the goalbox, the latter being $20.3 \mathrm{~cm}$ wide and $30.5 \mathrm{~cm}$ from front to back. When the experimenter pulled a counterweight, the startbox door opened and started a clock. When the subject entered the goalbox, the leading edge of the floor was depressed $2.5 \mathrm{~mm}$, stopping the clock, measuring running time.

\section{Procedure}

Sucrose concentration solutions of $16 \%$ and $4 \%$ were used with a shift group (16-4), a sucrose control group (4-4), and a tap water group (W). The 4-4 group experienced $4 \%$ sucrose throughout the 15 sessions of the study. The $16-4$ group received a $16 \%$ sucrose solution through Session 10; from Session 11 on, the $16-4$ animals experienced a reduction to $4 \%$. Finally, the $\mathrm{W}$ 
group animals were rewarded with tap water for the first 10 (preshift) sessions. There were five postshift sessions (11-15). Following several days of adaptation to a $23-\mathrm{h}$ food-and waterdeprivation schedule, subjects were trained on successive days to press the bar for continuous reinforcement; with each depression, the bar operated the magazine. Each session lasted 35 reinforcements (dipper presentations). Throughout the 15 sessions, all subjects were maintained on $23 \mathrm{~h}$ food and water deprivation. After its daily preshift operant chamber session each $16-4$ and each $4-4$ animal was given 20 min of free exploration in the runway, followed by access to food and water in the home cage for $1 \mathrm{~h}$. The $\mathrm{W}$ animals received food and water for $1 \mathrm{~h}$ following their experimental periods. Body weights were recorded daily. When the subjects were placed in the startbox at the beginning of each free exploration period, their running times to enter the goalbox were recorded.

Within $10 \mathrm{~min}$ after each session 11-15, each $16-4$ and 4-4 animal was given 10 test trials in the straight alley. Animals were tested in the runway under the same deprivation conditions as in the operant box. Each trial was begun by placing the animal in the startbox and opening the door $15 \mathrm{sec}$ later, regardless of the subject's orientation. No subject failed to traverse the runway and enter the goalbox.

Ten minutes after each runway trial on Days 1-15, aggression testing occurred for each of the animals in the 16-4 and 4-4 groups. Aggression testing involved placing one animal at a time in a cage for $3 \mathrm{~min}$, followed by the presentation of a bottle brush turned $180 \mathrm{deg}$ approximately once every $.50 \mathrm{sec}$ for 2 min (fighting time). The aggressive responses recorded in the 2 min were the frequency of brush bites and the latency of the second bite (the time between the first brush presentation and the second bite).

\section{RESULTS}

Body weight data (not presented here) indicated no significant difference between the three groups during the pre-or postshift phases.

The average number of barpresses made per minute was examined in the analysis of the operant box data.

It is clear from Table 1 that from Session 1 to Session 10, the 16-4 subjects performed at a higher level than the $4-4$ rats and the $\mathrm{W}$ animals responded at a lower level than either the $16-4$ or $4-4$ group. The mean number of barpresses per minute from Session 1 to Session 10 differed significantly between the three groups by an analysis of variance $[F(2,57)=4.61$, $p<.05]$. By Duncan's multiple comparisons, the differences between $W$ and each other group and between $16-4$ and $4-4$ were each significant $(p<.05)$. Table 1 indicates that on Session 11, the $16-4$ animals rapidly reduced the number of barpresses made to a level below that of the 4.4 (negative incentive contrast effects). The mean number of barpresses made from Session 11 to Session 12 differed statistically between $16-4$ and $4-4$ by analysis of variance $[F(1,38)=6.12$, $p<.05]$.

Mean running speed during the 10 preshift exploration days showed no significant difference between 16-4 and 4-4. The same lack of running speed significance was observed for $16-4$ vs. $4-4$ for any postshift session (11, $12,13,14$, or 15$)$. An analysis of variance was performed over mean speed for Postshift Days 11-12 $[F(1,38)=1.05, p>.05]$. The mean running speeds on these 2 postshift days were 312 and $302 \mathrm{~mm} / \mathrm{sec}$ for $4-4$ and 164 , respectively; in other words, a reduction in reward and consequent downward contrast effects in the operant box did not produce an increase in runway behavior relative to a constant-reward control group.

The average number of bites per minute was examined as another response measure. Table 2 presents these data. The mean number of bites per minute from Day 1 to Day 10 between $16-4$ and $4-4$ was not significant by an analysis of variance $[F(1,38)=2.01, p>.05]$. The mean latency of the second brush bite in the fightingtime period from Day 1 to Day 10 was also not statistically valid between $16-4$ and $4-4$ by analysis of variance $[F(1,38)=1.05, p>.05$. The latency means for $16-4$ and $4-4$ were 50.03 and 41.62 , respectively. That is to say, before the reduction in reward quantity, the experimental and control groups were alike in terms of aggressive tendencies.

The mean number of bites per minute on Test Days 11-12 was significantly different between $16-4$ and 4-4 by another analysis of variance $[\mathrm{F}(1,38)=4.96$, $\mathrm{p}<.05]$. The mean latency of the second bite over the

Table 1

Mean Barpresses per Minute

\begin{tabular}{|c|c|c|c|c|c|c|c|c|c|c|c|c|c|c|c|}
\hline \multirow[b]{2}{*}{ Group } & \multicolumn{15}{|c|}{ Session } \\
\hline & 1 & 2 & 3 & 4 & 5 & 6 & 7 & 8 & 9 & 10 & 11 & 12 & 13 & 14 & 15 \\
\hline $16-4$ & 7.5 & 13.6 & 20.1 & 26.8 & 26.6 & 35.1 & 36.7 & 38.1 & 38.2 & 37.9 & 6.2 & 7.3 & 9.6 & 11.4 & 13.0 \\
\hline $4-4$ & 6.8 & 8.5 & 10.1 & 13.7 & 12.9 & 15.6 & 16.8 & 16.0 & 17.1 & 15.9 & 15.1 & 14.9 & 15.1 & 15.3 & 15.1 \\
\hline W & 4.0 & 5.0 & 5.1 & 4.8 & 4.7 & 5.1 & 5.1 & 4.9 & 5.0 & 4.8 & 5.6 & 5.7 & 5.5 & 5.8 & 5.5 \\
\hline
\end{tabular}

Table 2

Mean Number of Bites per Minute

\begin{tabular}{|c|c|c|c|c|c|c|c|c|c|c|c|c|c|c|c|}
\hline \multirow[b]{2}{*}{ Group } & \multicolumn{15}{|c|}{ Aggression Testing Day } \\
\hline & 1 & 2 & 3 & 4 & 5 & 6 & 7 & 8 & 9 & 10 & 11 & 12 & 13 & 14 & 15 \\
\hline $16-4$ & 1.8 & 1.9 & 1.5 & 2.2 & 2.1 & 2.4 & 2.6 & 2.7 & 2.4 & 2.5 & 5.7 & 5.6 & 5.4 & 5.0 & 4.0 \\
\hline $4-4$ & 1.7 & 1.9 & 2.1 & 2.3 & 2.2 & 2.5 & 2.5 & 2.6 & 2.6 & 2.5 & 2.4 & 2.6 & 2.5 & 2.7 & 2.4 \\
\hline
\end{tabular}


11 th and 12 th days was likewise statistically valid by an analysis of variance $[\mathrm{F}(1,38)=4.99, \mathrm{p}<.05]$. The 16-4 mean latency was $9.6 \mathrm{sec}$, whereas the $4-4$ mean latency was $43.92 \mathrm{sec}$. In other words, a reduction in reward concentration that produced negative incentive contrast effects produced an increase in aggression in the downshifted subjects (relative to the constantconcentration control animals).

\section{DISCUSSION}

The present finding of negative contrast with a reduction in incentive concentration with a constant volume sucrose solution is not consonant with a number of incentive change studies that have used sucrose (e.g., Barnes \& Tombaugh, 1973; Dunham \& Kilps, 1969; Flaherty, Riley, \& Spear, 1973; Guttman, 1953; Rosen, 1966). The discrepant findings may be due to the different deprivation conditions selected by the present investigation (food and water deprivation) and the above-cited studies, which deprived subjects of only food or only water. There is good empirical support (e.g., Cleland, Williams, \& DiLollo, 1969; Ehrenfreund, 1971; Ehrenfreund \& Badia, 1962; Flaherty \& Kelly, 1973) for the assertion that more severe deprivation schedules (as employed in the present study) are more likely to produce negative contrast effects than are less severe (water or food alone) deprivation schedules. It should be noted that a negative contrast effect has been obtained with constant-volume sucrose solutions as reward with both food and water deprivation (Weinstein, 1970a, 1970b, 1978 ) and with frequency of the lick response (Vogel, Mikulka, \& Spear, 1968).

The finding that the water group responded at a significantly lower level during preshift than all other groups indicates that the sucrose concentrations used were all reinforcers; none was a punishing agent. A reinforcement is defined here as an event that produces a significantly higher level of performance as compared with a control group (in this case, the subjects exposed to water) that does not experience the event.

The fact that a reduction in reward quantity failed to produce greater running speed than a control level questions the frustration account of negative contrast. If reductions in reward to nonzero levels are similar to reduction to zero levels, then an increase in general level of behavior in the runway would be expected. Such increased vigor of responding is necessary to explain the downward effect as a frustrative phenomenon. If, however, decrements in reward quantity to nonzero levels produce a selective increase in aggressive behavior (and not general activity level), then the results of the present study would be expected. Thus, while frustrative nonreward has been consistently found to produce an increase in overall behavioral vigor in the double runway (e.g., Daly, 1968), reductions to nonzero reward levels would seem to selectively increase behavior, to wit, aggression. Indeed, Bolles (1967) has already suggested that specific behaviors change differentially within the increased vigor of responding seen in incentive reduction situations.

The present data agree with one other investigation's findings, both of which support an account of the downward effects (in humans) as due to aggression (e.g., Weinstein, 1977) and not frustration.

The present investigation suffers from a lack of validity data on brush bites and runway behavior as true measures of aggression and frustration, respectively. Without such correlative corroboration of the meaning of brush bites, for example, it is possible that brush biting represents, possibly, an appetitive consummatory response in the sense that the $16-4$ group is demonstrating an increase in some appetitive motivation resulting from the failure to receive the expected amount. Such validity data could be obtained by correlating other (supposed) aggression index with brush bites, and other measures of invigoration with runway behavior.

\section{REFERENCES}

Amsel, A. The role of frustrative nonreward in continuous situations. Psychological Bulletin, 1958, 55, 102-119.

Barnes, W., \& Tombaugh, T. M. Another failure to obtain negative incentive contrast following reductions in sucrose reward. Psychological Reports, 1973, 33, 801-802.

Bolles, R. C. Theory of motivation. New York: Harper \& Row, 1967.

Clelland, E. A., Williams, M. Y., \& DiLollo, V. Magnitude of negative incentive contrast effect in relation to drive level. Psychonomic Science, 1969, 15, 121-122.

DALY, H. B. Excitatory and inhibitory effects of complete and incomplete reward reductions in the double runway. Journal of Experimental Psychology, 1968, 76, 430-438.

DunhaM, P. J., \& KILPS, B. Shifts in magnitude of reinforcement: Confounded factor or contrast effects? Journal of Experimental Psychology, 1969, 79, 373-374.

EhrenfreUnd, D. Effect of drive on successive magnitude shift in rats. Journal of Comparative and Physiological Psychology, $1971,76,418-423$.

Ehrenfreund, D., \& Badia, P. Response strength as a function of drive level and pre- and postshift incentive magnitude. Journal of Experimental Psychology, 1962, 63, 468-471.

Flaherty, C. F., \& Kelly, J. Effects of deprivation state on successive negative contrast. Bulletin of the Psychonomic Society, 1973, 1, 365-367.

Flaherty, C. F., Riley, E. P., \& Spear, N. E. Effects of sucrose concentration and goal units or running behavior in the rat. Learning and Motivation, 1973, 4, 163-175.

Guttman, N. Operant conditioning, extinction, and periodic reinforcement in relation to concentration of sucrose used as reinforcing agent. Journal of Experimental Psychology, 1953, 46, 213-222.

Rosen, A. J. Incentive shift performance as a function of magnitude and number of sucrose rewards. Journal of Comparative and Physiological Psychology, 1966, 62, 487-490.

SpEnce, K. W. The roles of reinforcement and nonreinforcement in simple learning. In Behavior theory and learning. Englewood Cliffs, N.J: Prentice-Hall, 1960.

Vogel, J. R., Mikulka, P. J., \& Spear, N. E. Effects of shifts in sucrose and saccharine concentrations on licking behavior in the rat. Journal of Comparative and Physiological Psychology, 1968, 66, 661-666.

WEINSTE IN, L. Negative incentive contrast effect with saccharine vs. sucrose and partial reinforcement. Psychonomic Science, 1970, 21, 276-278. (a)

Weinstein, L. Negative incentive contrast with sucrose. Psychonomic Science, 1970, 19, 13-14. (b)

WEINSTEIN, L. Contrast effects in animal and human learning: Recent results and interpretations. Journal of Psychology, 1972, 81, 235-247.

Weinstein, L. Downward incentive contrast and the aggression hypothesis. International Research Communications System, Medical Science, 1977, 5, 40.

Weinstein, L. Negative and positive incentive contrast effects with saccharine versus sucrose. Journal of General Psychology, $1978,98,225-240$.

(Received for publication March 8, 1982.) 